\title{
Successful Treatment of Postpeak Stage Patients with Class II Division 1 Malocclusion Using Non-extraction and Multiloop Edgewise Archwire Therapy: A Report on 16 Cases
}

\author{
Jun Liu ${ }^{1}$, Ling Zou ${ }^{1}$, Zhi-he Zhao ${ }^{1 *}$, Neala Welburn ${ }^{2}$, Pu Yang ${ }^{1}$, Tian Tang ${ }^{1}, \mathrm{Yu} \mathrm{Li}^{1}$ \\ ${ }^{1}$ State Key Laboratory of Oral Diseases, West China College of Stomatology, Sichuan University, Chengdu, China \\ ${ }^{2}$ Faculty of Dentistry, University of British Columbia, Vancouver, British Columbia, Canada
}

\begin{abstract}
Jun Liu, Ling Zou, Zhi-he Zhao, Neala Welburn, Pu Yang,

Tian Tang, Yu Li. Successful treatment of postpeak stage patients with Class II Division 1 malocclusion using non-extraction and multiloop edgewise archwire therapy: A report on 16 cases. International Journal of Oral Science, 1(4): 207-216, 2009
\end{abstract}

Aim To determine cephalometrically the mechanism of the treatment effects of non-extraction and multiloop edgewise archwire (MEAW) technique on postpeak Class II Division 1 patients.

Methodology In this retrospective study, 16 postpeak Class II Division 1 patients successfully corrected using a non-extraction and MEAW technique were cephalometrically evaluated and compared with 16 matched control subjects treated using an extraction technique. Using CorelDRAW $^{\circledR}$ software, standardized digital cephalograms pre- and post-active treatments were traced and a reference grid was set up. The superimpositions were based on the cranial base, the mandibular and the maxilla regions,and skeletal and dental changes were measured. Changes following treatment were evaluated using the paired-sample $t$-test. Student's $t$-test for unpaired samples was used to assess the differences in changes between the MEAW and the extraction control groups.

Results The correction of the molar relationships comprised $54 \%$ skeletal change (mainly the advancement of the mandible) and $46 \%$ dental change. Correction of the anterior teeth relationships comprised 30\% skeletal change and $70 \%$ dental change.

Conclusion The MEAW technique can produce the desired vertical and sagittal movement of the tooth segment and then effectively stimulate mandibular advancement by utilizing the residual growth potential of the condyle.

Keywords cephalometry, Class II Division 1 malocclusion, mandibular advancement, multiloop edgewise archwire (MEAW), non-extraction, postpeak stage

Received Jul. 5, 2009; Revision accepted Aug. 15, 2009

\section{Introduction}

For Class II Division 1 patients who miss the peak stage, it is often hard to determine which treatment plan is most suitable. There is a plethora of choices - non-extraction correction through dentoskeletal adaptation, camouflage treatment through extraction of premolars, or orthognathic surgery for adults. Especially when it comes to a late adolescent or young adult who has a normally developed maxilla and a retrognathic mandible, the first of these options may have the least risks and lowest costs.

Publications about Class II Division 1 nonextraction correction through dentoskeletal adaptation in late adolescent and young adult patients are limited mainly to the use of removable and fixed functional appliances. A variety of treatment effects have been reported in the literature. McNamara described three young adult Class II patients trea- 
ted with removable functional (Fränkel) appliances but presented no major improvements in skeletal or posterior dental relationships (McNamara, 1984). Bakke and Paulsen demonstrated Herbst treatment in an almost full-grown male of 17 years whose retrognathism of the mandible was overcorrected with marked dentoalveolar changes, an increase in mandibular length and ramus height, apposition and remodelling of condylar heads and flattening of the temporal joint surface (Bakke and Paulsen, 1989). Ruf and Pancherz studied adolescent and young adult patients treated with the fixed Herbst appliance using magnetic resonance imaging and the results suggested condylar and glenoid fossa remodeling (Ruf and Pancherz, 1998; 1999; 2004). Nalbantgil et al. found that the Jasper Jumper corrected Class II discrepancies mostly through dentoalveolar changes in late-adolescent patients (Nalbantgil et al., 2005).

The multiloop edgewise archwire (MEAW) technique, having been invented to correct the open bite (Kim, 1987), has turned out to be a desirable remedy for sagittal discrepancies (Kim and Han, 2001; Sato, 1994). Furthermore, clinical practice shows that the MEAW technique is equally effective when used with pre-adjusted appliances. In this retrospective study, 16 postpeak Class II Division 1 patients who were successfully treated using a non-extraction and MEAW technique were selected. The purpose was to evaluate the effectiveness of this method for Class II discrepancy correction, and to determine cephalometrically the mechanism of the treatment effects.

\section{Materials and methods}

\section{Subjects}

The MEAW and non-extraction group consisted of 16 postpeak Class II Division 1 patients (9 females and 7 males), treated between 2003 and 2006 at the Department of Orthodontics, West China Hospital of Stomatology, Sichuan University, Chengdu, China. All were Chinese and their ages ranged from 13.5 to 23.2 years (mean $\pm \mathrm{SD}, 15.6 \pm$ 2.9 years). The patients were treated with either edgewise or pre-adjusted fixed appliances $(0.022 \times$ 0.028 inch slot $)$ and MEAW technique $(0.017 \times$
0.025 inch). The active treatment periods ranged from 13 to 37 months ( $25.4 \pm 8.3$ months). The patient inclusion criteria were:

1) The developmental age before treatment was postpeak stage, as judged by the stages of cervical vertebral maturation (O'Reilly and Yanniello, 1988);

2) Subjects had suffered a Class II Division 1 malocclusion caused by a normally developed maxilla and retrognathic mandible with at least an end-to-end ( $1 / 2$ cusp) Class II molar relationship bilateral;

3) The molar relationship and the anterior overjet were corrected or improved greatly, and the treatment effects were stable with no active force;

4) No tooth was extracted or missing except the $3^{\text {rd }}$ molar;

5) The cephalometric landmarks necessary for the analysis were identifiable.

For all subjects, the temporomandibular joints (TMJ) were examined regularly during the treatment.

Sixteen postpeak Class II Division 1 subjects with extraction of two maxillary first premolars or plus two mandibular premolars (first or second) for resolving the overjet, served as the control group. They comprised 11 females and 7 males (average age 15.9 years), who had been under treatment (28.1 \pm 6.6 months) at the same hospital. MEAW was not used in the control group. Parameters of the control group which might have influenced the results were carefully matched to those of the study group, including age, duration of active treatment, crowding in dental arches, and the distribution of the pattern of facial growth (both groups containing only one vertical growth pattern subject).

\section{Cephalometric analysis}

Standardized digital cephalometric radiographs in habitual occlusion had been taken using Orthoceph OC100D cephalostat (General Electric Company, Instrumentarium Corp., Imaging Division, Finland). Cephalograms taken at the start of treatment (T1) and after treatment (T2) were analyzed. The digital cephalograms of each patient were traced with CorelDRAW ${ }^{\circledR}$ software (version 11.0; Corel Corp., Canada) in a short period by one 


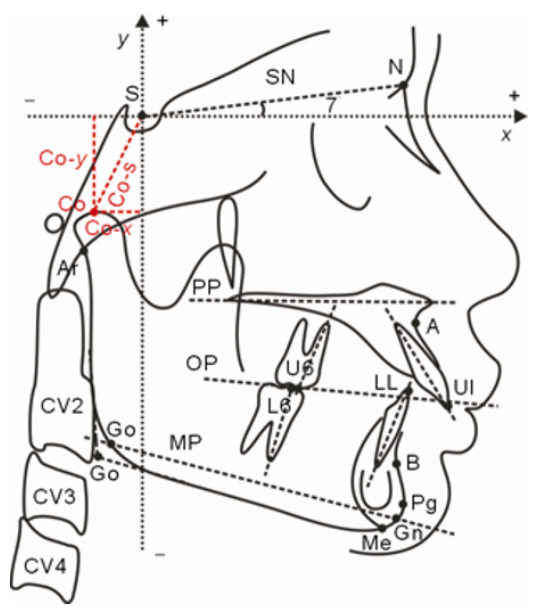

Figure 1 Measuring points and reference lines used in cephalometric analysis

Cephalometric reference points: S, sella; N, nasion; Co, condylion; Ar, articulare; A, point A; UI, upper central incisor; U6, upper first molar; LI, lower incisor; L6, lower first molar; B, point $\mathrm{B}$; $\mathrm{Me}$, menton; $\mathrm{Gn}$, gnathion; $\mathrm{Pg}$, pogonion; Go, gonion; Go', tangent gonion; $\mathrm{CV}$, cervical vertebral.

Linear measurements include Ar, Go, Pg, B, A, tip of the mesial cusp of L6 (L6), incisal edge of lower incisor (LI), tip of the mesial cusp of U6 (U6) and incisal edge of upper incisor (UI).

Angular measurements included NSAr (saddle angle), SArGo' (articular angle), ArGo'Me (gonial angle), SUM (sum of NSAr, SArGo' and ArGo'Me), SN-FOP (functional occlusal plane), SN-PP (palatal plane), SN-GoGn (mandibular plane), L6 axis, LI axis, U6 axis and UI axis. When the teeth axes (L6, LI, U6 and UI) were measured, the values of pre-treatment (T1) were recorded as $0^{\circ}$ and the values of post-active treatment (T2) recorded as positive if crowns tipped mesially or negative if crowns tipped distally. examiner (J.L.). Correction was made for linear enlargement $(100 \%)$. Tracing lines were set at $0.2 \mathrm{~mm}$ in width.

Cephalometric landmarks used for the analysis are listed in Figure 1. A reference grid was set up on pre-treatment (T1) cephalograms using Corel$\mathrm{DRAW}^{\circledR}$ software (Figure 1). The reference lines were those used in previous investigations (Nalbantgil et al., 2005). Briefly, the $x$-axis was a line constructed at $7^{\circ}$ relative to the $S$ - $N$ line and the $y$-axis was a line down perpendicular to $x$-axis through the S point. Taking condylion (Co) as an example, Co- $x$ means the distance from Co perpendicular to the $y$-axis; the value can be positive (on the left side of Sella $(\mathrm{S})$ ) or negative (on the right side of S). Co- $y$ means the distance from Co perpendicular to the $x$-axis; the value can be positive (on the upside of $\mathrm{S}$ ) or negative (on the downside of S). Co-S means the distance from Co to $S$; the value is always positive.

The method of superimposition for T1 and T2 cephalograms was based on the structural superimposition technique described and employed by some researcher (Björk, 1968; Björk and Skieller, 1983; Johnston, 1986). The superimpositions were completed and measured using CorelDRAW ${ }^{\circledR}$ software (Figure 2). Linear and angular measurements were made to the nearest $0.1 \mathrm{~mm}$ and $0.1^{\circ}$, respectively. The measuring points are listed in Figure 1.

\section{Statistical methods}

After an interval of 25 days, all cephalograms were traced, superimposed and re-measured.

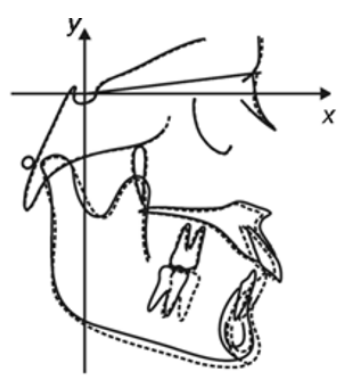

A

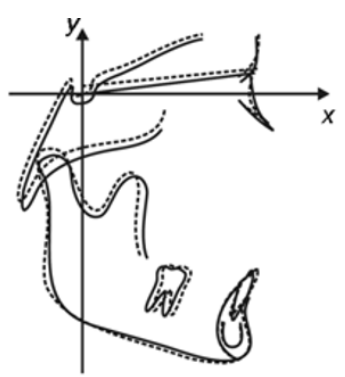

B

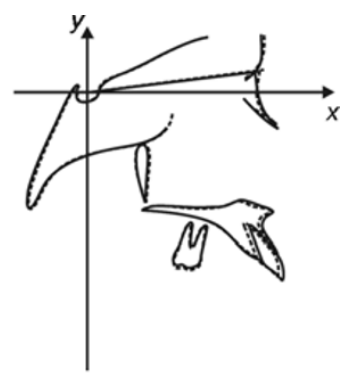

C

Figure 2 Superimpositional methods (Patient H.X.)

(A): Superimposition on cranial base; (B): Superimposition on mandible; (C): Superimposition on maxilla. T1, pre-treatment; T2, post-active treatment. 
Dahlberg's formula was used to calculate the method error. Differences between the two sets of measurements were insignificant. The method error did not exceed $0.1 \mathrm{~mm}$ and $0.6^{\circ}$ for the linear and angular measurements, respectively. For the final evaluation, the mean value of the duplicate registrations was used. The paired-sample $t$-test was used to evaluate the results of treatment for both the MEAW group and the control group. Student's $t$-test for unpaired samples was used to assess the differences in changes in each skeletal variable between the two groups during the treatment period.

\section{Results}

\section{Dentoskeletal changes}

Data for the MEAW group before and after the active treatment show that the correction of the malocclusion by non-extraction and MEAW was achieved both by skeletal and dental changes (Table 1). The correction of the molar relationships comprised about $54 \%$ skeletal change (mainly the advancement of the mandible) and $46 \%$ dental change (mesial movement of the lower molars), whereas about $30 \%$ of the correction of the anterior teeth relationships was attributed to skeletal change (advancement of the mandible) and $70 \%$ to dental change (protraction of the lower incisors and retraction of the upper incisors). Whole mandibular displacement and condylar growth and modification contributed to the forward and downward movement of the mandibular body (Table 1, superimpositions on cranial base and on mandible). The results suggest that modification might have occurred not only in the condyle but also probably in the glenoid fossa. There was no significant change in the SN-FOP (functional occlusal plane).

Condylar growth and modification were found in both the non-extraction and MEAW group and the control group, but the former group showed a greater change in the condyle (Table 2, superimpositions on mandible, Co-S) $(P<0.05)$. Furthermore, compared with the control group, the downward movement of the whole mandible was significant (Table 2, superimpositions on cranial base) $(P<0.05)$.

\section{TMJ examination}

No obvious signs or symptoms of temporomandibular disorder were found throughout the duration of the treatment. Some patients who had complained of TMJ click when opening or closing the mouth before the treatment showed that the symptom was relieved simultaneously with Class II correction. Although long term elastics were applied carefully to help the TMJ remolding (for example, patient H.X. had worn the elastics for 24 months), the joints did not develop TMJ disorder. One reason was that the elastic forces were light and controlled.

\section{Case presentation}

H.X., a 16.5-year-old male, presented for correction of Class II Division 1 malocclusion characterized by a nearly normally developed maxilla and retrognathic mandible (Figures 3A, 3B, 3C and $3 \mathrm{~J})$. A non-extraction treatment was planned with the possible need for extractions if the mandible could not be advanced. The upper and lower arches were banded and bonded through the second molars. The arches were firstly aligned and leveled with 0.014 inch NiTi and $0.016 \times 0.022$ inch NiTi. Then, $0.017 \times 0.025$ inch stainless wires (s.s.) with expansion and an exaggerated curve of Spee in the upper arch and a reverse curve in the lower arch were placed to level the arches. Light Class II elastics were worn for leveling and mandibular advancement. After 4 months, a dual bite was present and the mandibular retracted when performing functions. Then MEAW $(0.018 \times 0.025$ inch s.s., with tip-back bends and step bends for posterior extrusion) plus light short Class II elastics (3/16 inch, $3.5 \mathrm{oz}, 3 \mathrm{M}$ Uniteck, Monrovia, USA) were applied (Figure 4A). After 14 months, the mandible showed a steady advancement by $1 / 2$ cusp. At the 35th month, the malocclusion was largly corrected and stabe, and active treatment was terminated (Figures 3D, 3E, $3 \mathrm{~F}$ and $3 \mathrm{~K}$ ). Figures $2 \mathrm{~A}, 2 \mathrm{~B}$ and $2 \mathrm{C}$ show his cephalometric superpositions at $\mathrm{T} 1$ and $\mathrm{T} 2$. A pair of Hawley retainers was set in place for retention. Figures 3G, 3H, 3I and $3 \mathrm{~L}$ show his stable occlusion 12 months after the completion of active treatment. 
Table 1 Comparison of the cephalometric changes in the non-extraction and MEAW group $(n=16)$

\begin{tabular}{|c|c|c|c|c|c|}
\hline \multirow[t]{2}{*}{ Variable } & \multicolumn{2}{|c|}{ Pre-treatment } & \multicolumn{2}{|c|}{ Post-treatment } & \multirow[t]{2}{*}{$P$} \\
\hline & mean & SD & mean & SD & \\
\hline \multicolumn{6}{|c|}{ Superimpositions on cranial base } \\
\hline Co- $x(\mathrm{~mm})$ & -11.5 & 2.3 & -10.5 & 2.3 & $0.036^{*}$ \\
\hline Co-y $(\mathrm{mm})$ & -20.3 & 1.9 & -21.1 & 2.0 & $0.085^{\star}$ \\
\hline Co-S (mm) & 23.6 & 2.3 & 23.6 & 2.5 & 0.962 \\
\hline $\operatorname{Ar}-x(\mathrm{~mm})$ & -15.1 & 2.5 & -14.3 & 2.4 & 0.055 \\
\hline $\operatorname{Ar}-y(\mathrm{~mm})$ & -33.2 & 2.0 & -33.7 & 2.3 & 0.065 \\
\hline $\operatorname{Ar}-\mathrm{S}(\mathrm{mm})$ & 36.5 & 2.7 & 36.7 & 2.9 & 0.438 \\
\hline $\operatorname{NSAr}\left({ }^{\circ}\right)$ & 126.6 & 4.3 & 125.5 & 3.9 & 0.064 \\
\hline SArGo' $\left({ }^{\circ}\right)$ & 151.1 & 6.6 & 152.5 & 6.6 & 0.255 \\
\hline $\operatorname{ArGo} \mathrm{Me}\left({ }^{\circ}\right)$ & 114.0 & 6.1 & 114.0 & 6.2 & 0.993 \\
\hline $\operatorname{SUM}\left({ }^{\circ}\right)$ & 391.8 & 6.0 & 392.1 & 6.4 & 0.666 \\
\hline Go-x (mm) & -8.1 & 3.4 & -7.4 & 4.0 & 0.218 \\
\hline Go-y $(\mathrm{mm})$ & -76.5 & 5.4 & -78.5 & 5.6 & $0.000^{* * *}$ \\
\hline Go-S (mm) & 77.4 & 5.7 & 78.9 & 5.8 & $0.008^{* *}$ \\
\hline $\mathrm{Pg}-x(\mathrm{~mm})$ & 60.2 & 5.1 & 61.3 & 6.2 & 0.053 \\
\hline $\mathrm{Pg}-y(\mathrm{~mm})$ & 92.9 & 9.7 & 95.4 & 9.6 & $0.000^{* * *}$ \\
\hline $\mathrm{Pg}-\mathrm{S}(\mathrm{mm})$ & 112.0 & 8.5 & 115.3 & 7.9 & $0.000^{* * *}$ \\
\hline SN- FOP $\left(^{\circ}\right)$ & 19.3 & 4.7 & 18.5 & 5.2 & 0.444 \\
\hline SN-PP $\left({ }^{\circ}\right)$ & 12.2 & 3.2 & 11.4 & 3.0 & $0.038^{*}$ \\
\hline SN-GoGn $\left({ }^{\circ}\right)$ & 30.8 & 5.7 & 30.4 & 6.6 & 0.358 \\
\hline L6-x $(\mathrm{mm})$ & 38.8 & 4.5 & 41.4 & 4.2 & $0.000^{* * *}$ \\
\hline U6-x (mm) & 38.9 & 4.2 & 39.5 & 4.2 & $0.018^{*}$ \\
\hline B- $x(\mathrm{~mm})$ & 59.2 & 4.7 & 60.8 & 5.3 & $0.013^{*}$ \\
\hline B-y $(\mathrm{mm})$ & -84.2 & 4.7 & -86.0 & 4.7 & $0.003^{* *}$ \\
\hline $\mathrm{B}-\mathrm{S}(\mathrm{mm})$ & 103.0 & 5.0 & 105.6 & 4.8 & $0.000^{* * *}$ \\
\hline $\mathrm{A}-x(\mathrm{~mm})$ & 65.1 & 3.6 & 65.9 & 3.7 & $0.015^{*}$ \\
\hline A-y $(\mathrm{mm})$ & -48.0 & 4.1 & 48.0 & 4.7 & 0.919 \\
\hline A-S $(\mathrm{mm})$ & 80.9 & 4.2 & 81.6 & 4.4 & $0.012^{*}$ \\
\hline \multicolumn{6}{|c|}{ Superimpositions on mandible } \\
\hline Co- $x(\mathrm{~mm})$ & -11.8 & 2.1 & -12.3 & 2.0 & 0.200 \\
\hline Co-y $(\mathrm{mm})$ & -20.6 & 2.1 & -18.8 & 2.0 & $0.004^{* *}$ \\
\hline Co-S (mm) & 23.6 & 2.5 & 22.1 & 2.1 & $0.003^{* *}$ \\
\hline Go-x (mm) & -7.9 & 3.2 & -8.7 & 3.8 & $0.011^{*}$ \\
\hline Go-y $(\mathrm{mm})$ & -76.2 & 5.4 & -76.3 & 5.4 & 0.831 \\
\hline Go-S (mm) & 77.1 & 5.2 & 77.2 & 5.3 & 0.842 \\
\hline B- $x(\mathrm{~mm})$ & 58.9 & 4.6 & 58.9 & 4.5 & 0.464 \\
\hline B-y $(\mathrm{mm})$ & -82.1 & 4.8 & -81.9 & 4.3 & 0.186 \\
\hline B-S (mm) & 101.6 & 5.2 & 101.3 & 4.6 & 0.106 \\
\hline L6-x (mm) & 38.9 & 4.4 & 40.1 & 4.2 & $0.000^{* * *}$ \\
\hline L6-y (mm) & -62.4 & 4.0 & -61.0 & 4.0 & $0.000^{* * *}$ \\
\hline L6-S (mm) & 74.4 & 4.2 & 74.0 & 4.2 & 0.089 \\
\hline L6 $\operatorname{axis}\left({ }^{\circ}\right)$ & 0.0 & 0 & -4.2 & 2.8 & $0.000^{* * *}$ \\
\hline LI-x (mm) & 65.5 & 3.9 & 67.4 & 3.7 & $0.000^{* * *}$ \\
\hline LI-y $(\mathrm{mm})$ & -63.1 & 4.2 & -63.8 & 4.0 & $0.026^{*}$ \\
\hline LI-S (mm) & 91.3 & 4.0 & 93.1 & 3.7 & $0.000^{* * *}$ \\
\hline LI axis $\left({ }^{\circ}\right)$ & 0.0 & 0.0 & 6.7 & 3.8 & $0.000^{* * *}$ \\
\hline
\end{tabular}




\begin{tabular}{|c|c|c|c|c|c|}
\hline \multirow[t]{2}{*}{ Variable } & \multicolumn{2}{|c|}{ Pre-treatment } & \multicolumn{2}{|c|}{ Post-treatment } & \multirow[t]{2}{*}{$P$} \\
\hline & mean & SD & mean & SD & \\
\hline \multicolumn{6}{|c|}{ Superimpositions on maxilla } \\
\hline $\mathrm{A}-x(\mathrm{~mm})$ & 64.9 & 3.7 & 64.9 & 3.7 & 0.917 \\
\hline A-y $(\mathrm{mm})$ & 46.5 & 4.1 & 46.5 & 4.0 & 0.984 \\
\hline A-S $(\mathrm{mm})$ & 79.6 & 4.3 & 79.5 & 4.2 & 0.559 \\
\hline U6-x (mm) & 38.6 & 4.0 & 38.2 & 4.0 & 0.219 \\
\hline U6-y $(\mathrm{mm})$ & -62.6 & 4.0 & -63.1 & 3.9 & $0.026^{*}$ \\
\hline U6-S (mm) & 73.6 & 4.3 & 74.0 & 3.9 & 0.203 \\
\hline U6 axis $\left({ }^{\circ}\right)$ & 0.0 & 0.0 & 2.2 & 2.9 & $0.002^{* *}$ \\
\hline $\mathrm{UI}-x(\mathrm{~mm})$ & 72.0 & 4.2 & 70.3 & 3.8 & $0.000^{* * *}$ \\
\hline $\mathrm{UI}-y(\mathrm{~mm})$ & -66.3 & 4.5 & -67.4 & 4.6 & $0.000^{* * *}$ \\
\hline UI-S (mm) & 97.4 & 4.3 & 96.9 & 3.9 & $0.024^{*}$ \\
\hline Ul axis $\left({ }^{\circ}\right)$ & 0.0 & 0.0 & -4.7 & 6.1 & $0.001^{* *}$ \\
\hline
\end{tabular}

$* P<0.05, * * P<0.01, * * * P<0.001$. Figures in italics and bold were statistically significant.

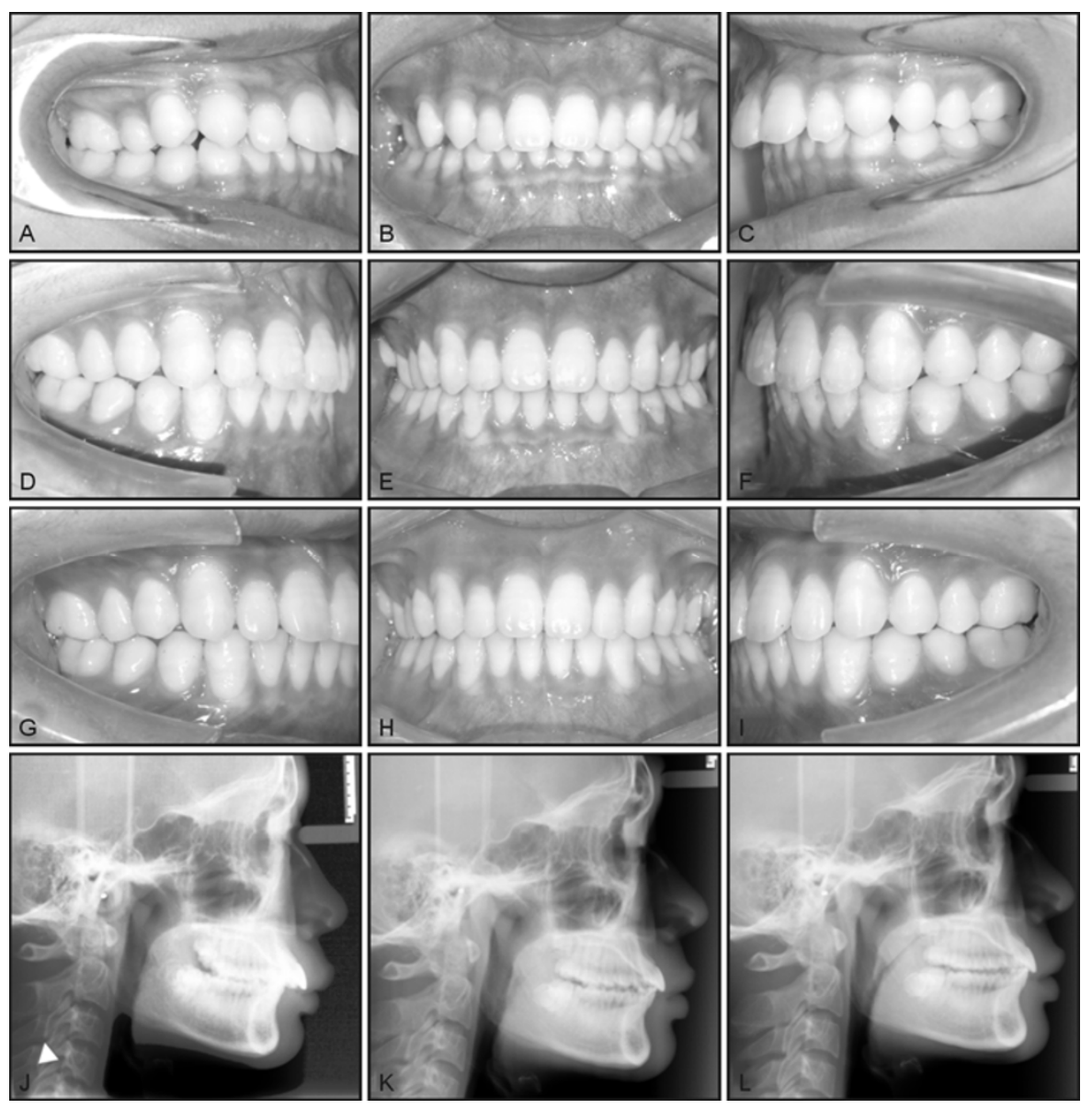

Figure 3 Case presentation of Patient H.X. whose malocclusion was successfully corrected by non-extraction and MEAW therapy

(A), (B) and (C): Intraoral photos before treatment showed nearly 3/4 cusp Class II molar relationship; (D), (E) and (F): 35 months later, intraoral photos taken immediately after brackets were removed; $(\mathrm{G}),(\mathrm{H})$ and $(\mathrm{I}): 12$ months later when the patient wore a Hawley retainer and made a return visit, intraoral photos show a stable occlusion; (J): Pre-treatment cephalogram, note the shape of the $4^{\text {th }}$ cervical vertebra which indicated that the patient was in the postpeak stage; (K): Post-active treatment cephalogram; (L): Cephalogram taken 12 months after the completion of active treatment. 
Table 2 Comparison of the skeletal changes between the non-extraction and MEAW group $(n=16)$ and the control group $(n=16)$

\begin{tabular}{|c|c|c|c|c|c|}
\hline \multirow[t]{2}{*}{ Skeletal variable } & \multicolumn{2}{|c|}{ Non-extraction and MEAW } & \multicolumn{2}{|c|}{ Control } & \multirow[t]{2}{*}{$P$} \\
\hline & Change & SD & Change & SD & \\
\hline \multicolumn{6}{|c|}{ Superimpositions on cranial base } \\
\hline Co- $x(\mathrm{~mm})$ & $1.0^{*}$ & 1.8 & 0.7 & 1.2 & 0.618 \\
\hline Co-y $(\mathrm{mm})$ & $-0.8^{*}$ & 1.3 & -0.3 & 0.5 & 0.368 \\
\hline Co-S (mm) & 0.0 & 1.6 & 0.0 & 1.0 & 0.959 \\
\hline $\operatorname{Ar}-x(\mathrm{~mm})$ & 0.8 & 1.7 & 0.3 & 0.6 & 0.606 \\
\hline $\operatorname{Ar}-y(m m)$ & -0.5 & 0.9 & -0.2 & 0.7 & 0.333 \\
\hline $\operatorname{Ar}-\mathrm{S}(\mathrm{mm})$ & 0.2 & 1.2 & 0.1 & 0.7 & 0.744 \\
\hline $\operatorname{NSAr}\left({ }^{\circ}\right)$ & -1.1 & 2.2 & -0.3 & 1.2 & 0.845 \\
\hline SArGo' $\left({ }^{\circ}\right)$ & 1.4 & 4.6 & 1.6 & 3.2 & $0.030^{*}$ \\
\hline $\operatorname{ArGo} o^{\prime} \mathrm{Me}\left({ }^{\circ}\right)$ & 0.0 & 2.8 & 0.7 & 1.6 & 0.423 \\
\hline $\operatorname{SUM}\left({ }^{\circ}\right)$ & 0.3 & 2.6 & 1.6 & 3.4 & 0.293 \\
\hline Go- $x(\mathrm{~mm})$ & 0.7 & 2.2 & 0.0 & 1.7 & 0.398 \\
\hline Go-y $(\mathrm{mm})$ & $-2.0^{* * *}$ & 1.7 & $-0.7^{*}$ & 0.9 & $0.034^{*}$ \\
\hline Go-S (mm) & $1.5^{\star *}$ & 1.9 & 0.5 & 0.9 & $0.016^{*}$ \\
\hline $\mathrm{Pg}-x(\mathrm{~mm})$ & $1.9^{* *}$ & 2.4 & 0.9 & 2.8 & 0.308 \\
\hline $\mathrm{Pg}-y(\mathrm{~mm})$ & $-2.5^{\star \star \star}$ & 2.4 & $-1.1^{*}$ & 1.4 & $0.046^{*}$ \\
\hline $\mathrm{Pg}-\mathrm{S}(\mathrm{mm})$ & $3.3^{* * *}$ & 2.1 & $1.8^{* * *}$ & 1.1 & $0.015^{*}$ \\
\hline SN-PP $\left(^{\circ}\right)$ & $-0.8^{*}$ & 1.5 & 0.1 & 1.4 & 0.100 \\
\hline SN-GoGn $\left({ }^{\circ}\right)$ & -0.4 & 1.8 & 0.2 & 2.1 & 0.444 \\
\hline $\mathrm{B}-x(\mathrm{~mm})$ & $1.6^{*}$ & 2.3 & 0.9 & 2.3 & 0.495 \\
\hline B-y (mm) & $-1.8^{* *}$ & 2.1 & -0.2 & 1.9 & $0.025^{*}$ \\
\hline B-S (mm) & $2.7^{* * *}$ & 1.8 & 0.6 & 1.1 & $0.004^{* *}$ \\
\hline $\mathrm{A}-x(\mathrm{~mm})$ & $0.7^{*}$ & 1.1 & -0.1 & 1.0 & 0.066 \\
\hline A-y $(\mathrm{mm})$ & 0.0 & 1.4 & -0.2 & 0.7 & 0.773 \\
\hline A-S $(m m)$ & $0.7^{*}$ & 1.0 & 0.0 & 0.7 & 0.055 \\
\hline \multicolumn{6}{|c|}{ Superimpositions on mandible } \\
\hline Co- $x(\mathrm{~mm})$ & -0.5 & 1.4 & -0.8 & 1.1 & 0.360 \\
\hline Co-y $(\mathrm{mm})$ & $1.8^{* *}$ & 2.1 & $1.2^{* *}$ & 1.2 & 0.185 \\
\hline Co-S (mm) & $-1.5^{* *}$ & 1.7 & -0.5 & 1.1 & $0.025^{*}$ \\
\hline Go-x $(\mathrm{mm})$ & $-0.8^{*}$ & 1.1 & $-0.9^{*}$ & 1.8 & 0.842 \\
\hline Go-y $(\mathrm{mm})$ & -0.1 & 1.1 & 0.3 & 1.0 & 0.371 \\
\hline Go-S (mm) & 0.1 & 1.1 & 0.1 & 0.9 & 0.957 \\
\hline $\mathrm{B}-x(\mathrm{~mm})$ & 0.0 & 0.6 & -0.6 & 0.8 & 0.746 \\
\hline B-y $(\mathrm{mm})$ & 0.2 & 0.8 & -0.1 & 0.6 & 0.618 \\
\hline B-S (mm) & -0.3 & 0.7 & -0.5 & 0.8 & 0.340 \\
\hline \multicolumn{6}{|c|}{ Superimpositions on maxilla } \\
\hline A- $x(\mathrm{~mm})$ & 0.0 & 0.4 & -0.5 & 0.7 & 0.169 \\
\hline A-y $(\mathrm{mm})$ & 0.0 & 0.7 & 0.0 & 1.0 & 0.984 \\
\hline $\mathrm{A}-\mathrm{S}(\mathrm{mm})$ & -0.1 & 0.9 & -0.2 & 0.9 & 0.495 \\
\hline
\end{tabular}

$* P<0.05, * * P<0.01, * * * P<0.001$. Figures in italics and bold were statistically significant. 


\section{Discussion}

\section{Mechanism of MEAW effects}

One of our most important findings was that the residual growth potential (Lewis and Roche, 1988; Behrents, 1985; Bjork, 1963) in postpeak stage patients, even in young adults, had been utilized by the MEAW technique during the correction of Class II malocclusion. Modified MEAW with tipback bends and step bends for posterior extrusion plus short Class II elastics (Figure 4A) could produce the desired vertical and sagittal movement of the tooth segment. Temporary occlusal interferences might be present in posterior teeth, promoting mandibular advancement and TMJ modification. Construction of an ideal cusp-fossa relationship could then be induced by both skeletal and dental adjustments. The occurrence of the skeletal changes would contribute to longer treatment duration but greater improvement of the profile and more stability of the active treatment effects.

The dentoalveolar changes were equally important for the correction of Class II Division 1 discrepancy. The mesial movement of the lower molars accounted for nearly $50 \%$ of the success of correction of the molar relationships, under the function of short Class II elastics (Figure 4A). The incisors exhibited even more displacements during the correction of sagittal discrepancies than the molars, by protraction of the lower incisors and retraction of the upper incisors. The alignment and leveling of the arches and the moderate expansion of the upper arch (Voudouris and Kuftinec, 2000) eliminated possible occlusal interferences to the advancement of the mandible, which was a precondition for condylar displacement, growth and modification.

The extrusion of molars, caused by the combination of both step bends of MEAW and short Class II elastics therapy, increased the posterior dentoalveolar height. We hypothesize that it might act as a powerful pivot in the whole mandible "lever" (Figures 4B and 4C). The short Class II elastics might be another key stimulation, performing the function of a motive force in a Type I lever (Figures 4B and 4C). The traction force of the viscoelastic tissue (McNamara, 2000) loaded on the condyle (the resistance of the "lever") might then stimulate condyle growth modification effectively.

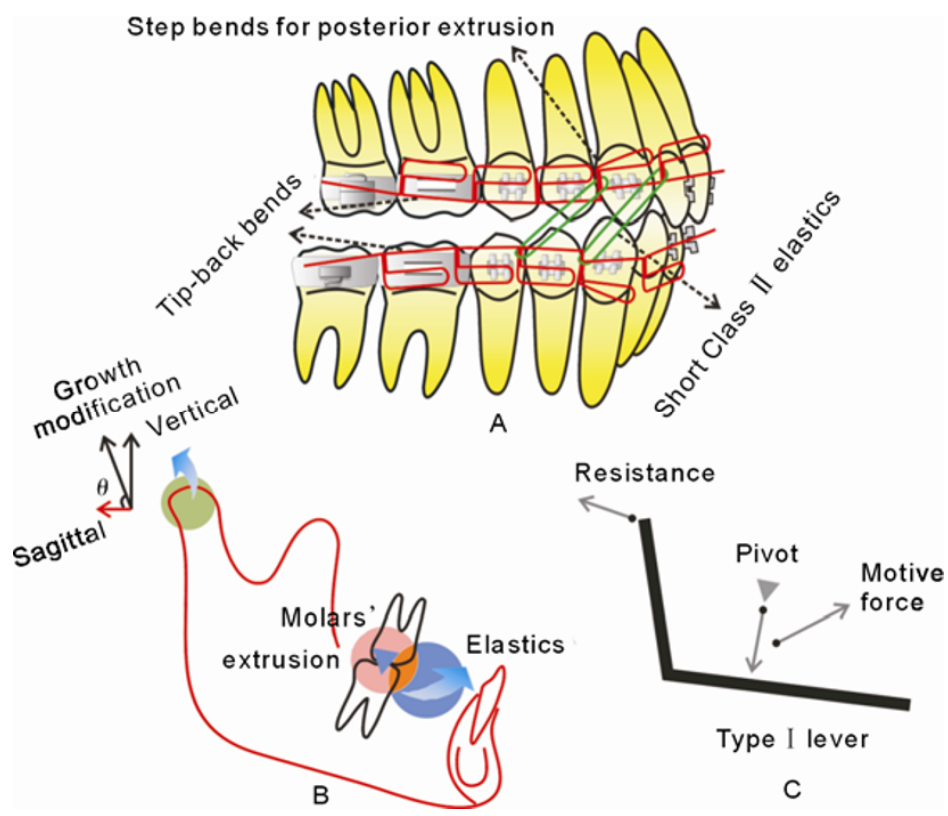

Figure 4 Analysis of MEAW mechanism

(A): MEAW with tip-back bends and step bends at the $2^{\text {nd }}$ loops plus the use of short Class II elastics for posterior extrusion and distal tipping. (B): Schematic diagram of the biomechanical analysis of the MEAW effects on condylar modification. (C): Force diagram of the MEAW effects on condylar modification. Refer to text for detailed explanation. 


\section{Change of occlusal plane}

It had been hypothesized that mandibular advancement is related to anticlockwise (upwards) rotation of the occlusal plane. Thus, we did not adopt Pancherz's superimposition method for quantitative evaluation of condylar growth modification (Shen and Darendeliler, 2006; Pancherz and Hägg, 1985), which used the original occlusal line as the reference line. However, our study did not show a significant change in SN-FOP.

\section{Influence of pattern of facial growth}

The 16 patients in the non-extraction and MEAW group contained 11 hypodivergent, 4 normodivergent and 1 hyperdivergent skeletal types. It has been suggested that the pattern of facial growth might have a connection with the curative effects. Björk pointed that the growth of the condyle was directed sagittally when the mandibular base was flat (Björk, 1963). Thus, when the residual growth potential of the condyle was guided and stimulated by the MEAW technique, the mandible of the hypodivergent type might have more sagittal advancement than that of the hyperdivergent type (as shown in Figure 4B, the hypodivergent type possibly having a smaller angle $\theta$ ).

Weak masticatory muscles are associated with hyperdivergence whereas hypodivergence is usually linked with powerful masticatory muscles. The muscles of hypodivergent type might adapt the modification of condyle for the extrusion of molars whereas the muscles of hyperdivergent type might withstand the force loading. So it might be disadvantageous to extrude the molars in the postpeak hyperdivergence cases because the mandible could rotate clockwise to aggravate the hyperdivergence. For these cases, efforts for correction of the Class II relationship should be made in dental modification by extraction of the third molars and distal tipping of the upper molars by MEAW tip back bend (Figure 4A).

\section{Indications}

For some borderline skeletal Class II cases in postpeak stage, MEAW technique can be used as an alternative to orthognathic surgery. Although the 16 patients in this study showed a satisfactory correction of sagittal discrepancies without extraction of premolars, it is still difficult to anticipate the exact orthodontic effects for a new postpeak Class II Division 1 patient. Many factors can affect the result, such as the patient's compliance, the residual potential of growth (biological age), and possibly the duration and the magnitude of the elastics, the facial growth pattern and the functional status of the masticatory muscles. However, cases of severe skeletal Class II malocclusion should be treated with orthognathic surgery.

\section{Conclusions}

Sixteen postpeak Class II Division 1 patients successfully-corrected with non-extraction and MEAW technique were cephalometrically evaluated. The correction of the molar relationships comprised 54\% skeletal change (mainly the advancement of the mandible) and $46 \%$ dental change; the correction of the anterior teeth relationships comprised $30 \%$ skeletal change and $70 \%$ dental change. MEAW technique together with short Class II elastics can produce the desired vertical and sagittal movement of the teeth or dentoalveolar segment and may stimulate mandibular advancement by utilizing the residual growth potential of the condyle.

\section{References}

Bakke M, Paulsen HU (1989). Herbst treatment in late adolescence: clinical, electromyographic, kinesiographic, and radiographic analysis of one case. Eur J Orthod, 11(4): 397-407.

Behrents RG (1985). Growth in the aging craniofacial skeleton. Craniofacial growth series. Ann Arbor: Centre for Human Growth and Development, University of Michigan.

Björk A (1963). Variations in the growth pattern of the human mandible: longitudinal radiographic study by the implant method. J Dent Res, 42(1): 400-411.

Björk A (1968). The use of metallic implants in the study of facial growth in children: method and application. $A m$ J Phys Anthrop, 29(2): 243-254.

Björk A, Skieller V (1983). Normal and abnormal growth of the mandible. A synthesis of longitudinal cephalo- 
metric implant studies over a period of 25 years. Eur $J$ Orthod, 5(1): 1-46.

Johnston LE (1986). A comparative analysis of Class II treatments. In: Vig PS and Ribbens KA, eds. Science and clinical judgement in orthodontics. Monograph no. 19. Craniofacial growth series. Ann Arbor: Centre for Human Growth and Development, University of Michigan. p. 103-148.

Kim YH (1987). Anterior openbite and its treatment with multiloop edgewise archwire. Angle Orthod, 57(4): 290321.

Kim YH, Han UK (2001). The versatility and effectiveness of the Multiloop Edgewise Archwire (MEAW) in treatment of various malocclusions. World J Orthod, 2(3): 208-218

Lewis AB, Roche AF (1988). Late growth changes in the craniofacial skeleton. Angle Orthod, 58(2): 127-135.

McNamara JA (2000). Maxillary transverse deficiency. Am J Orthod Dentofacial Orthop, 117(5): 567-570.

McNamara JA Jr (1984). Dentofacial adaptations in adult patients following functional regulator therapy. $\mathrm{Am} \mathrm{J}$ Orthod, 85(1): 57-71.

Nalbantgil D, Arun T, Sayinsu K, Fulya I (2005). Skeletal, dental and soft-tissue changes induced by the Jasper Jumper appliance in late adolescence. Angle Orthod, 75(3): 426-436.

O'Reilly MT, Yanniello GJ (1988). Mandibular growth changes and maturation of cervical vertebrae-A longitudinal cephalometric study. Angle Orthod, 58(2): 179-
184.

Pancherz H, Hägg U (1985). Dentofacial orthopedics in relation to somatic maturation. An analysis of 70 consecutive cases treated with the Herbst appliance. $\mathrm{Am}$ J Orthod, 88(4): 273-287.

Ruf S, Pancherz H (1998). Temporomandibular joint growth adaptation in Herbst treatment: a prospective magnetic resonance imaging and cephalometric roentgenographic study. Eur J Orthod, 20(4): 375-388.

Ruf S, Pancherz H (1999). Dentoskeletal effects and facial profile changes in young adults treated with the Herbst appliance. Angle Orthod, 69(3): 239-246.

Ruf S, Pancherz H (2004). Orthognathic surgery and dentofacial orthopedics in adult Class II Division 1 treatment: mandibular sagittal split osteotomy versus Herbst appliance. Am J Orthod Dentofacial Orthop, 126(2): 140-152.

Sato S (1994). Case report: developmental characterization of skeletal Class III malocclusion. Angle Orthod, 64(2): 105-112.

Shen G, Darendeliler MA (2006). Cephalometric evaluation of condylar and mandibular growth modification: a review. Orthod Craniofac Res, 9(1): 2-9.

Voudouris JC, Kuftinec MM (2000). Improved clinical use of Twin-block and Herbst as a result of radiating viscoelastic tissue forces on the condyle and fossa in treatment and long-term retention: growth relativity. $\mathrm{Am}$ J Orthod Dentofacial Orthop, 117(3): 247-266.

*Corresponding author: Zhi-he Zhao

Address: Department of Orthodontics, West China Hospital of Stomatology, Sichuan University, No.14, 3rd section, Renmin South Road, Chengdu 610041, China.

Tel: 86-28-85503645_Fax: 86-28-85582167_E-mail: zhaozhihe1963@yahoo.com.cn 